\title{
A linguagem da homilia na Exortação Evangelii Gaudium e a contribuição da hermenêutica bíblica de Paul Ricoeur
}

\author{
The language of the homily in the Evangelii Gaudium Exhortation \\ and the contribution of Paul Ricoeur's biblical hermeneutics
}

Jonas Emerim Velho ${ }^{1}$

\section{Resumo}

A Exortação Evangelii Gaudium, que trata do anúncio do Evangelho no mundo atual, pede que haja na homilia uma linguagem que exprima o coração do Evangelho. Para cumprir tal tarefa, a homilia deve servir-se de uma hermenêutica bíblica que lhe ajude a encontrar o núcleo da mensagem dos textos bíblicos. Nesse trabalho apresenta-se alguns elementos da teoria hermenêutica de Paul Ricoeur, e por fim apontamentos práticos para a linguagem da homilia segundo a Evangelii Gaudium. Espera-se que a teoria ricoeuriana possa ajudar na exegese bíblica para que a pregação da Palavra de Deus cumpra sua missão no contexto hodierno.

Palavras-chave: Evangelii Gaudium. Paul Ricoeur. Homilia

\section{Abstract}

The Exhortation Evangelii Gaudium, which delas with the proclamation of the Gospel in today's world, asks that there be a language in the homily that expresses the heart of the Gospel. To accomplish this task, the homily must use biblical hermeneutics to help it find the core message of the biblical texts. This work presentes some elements of Paul Ricoer's hermeneutic theory, and finally practical notes for the language of the homily according to Evangelli Gaudium. It is hoped that the Ricoeurian theory can help in biblical exegesis so that the preaching of the World of God fulfills its mission in today's contexto.

Keywords: Evangelii Gaudium. Paul Ricoeur. Homily.

\section{Introdução}

A primeira Exortação Apostólica do Papa Francisco, Evangelii Gaudium, trata do anúncio do Evangelho no mundo atual. Todas as orientações e

\footnotetext{
${ }^{1}$ Presbítero da Diocese de Criciúma - SC. Bacharel em Filosofia e em Teologia. Mestrando em Teologia Sistemática pela PUCRS.

E-mail: jonasemerimvelho@yahoo.com.br
}

Opinião Filosófica - ISSN: 2178-1176 - Editora Fundação Fênix. www.fundarfenix.com.br 
apontamentos do Pontífice para a evangelização vão em direção a um retorno ao núcleo fundamental do anúncio cristão, o querigma. Destaca-se que dos números 135 a 159, Francisco aborda o tema da homilia, trazendo orientações concretas para sua preparação, tendo em vista a importância da homilia como espaço privilegiado de anúncio da Palavra de Deus. Momento onde a Igreja realiza sua missão de evangelizar.

Em sintonia com a Exortação, também a homilia deve exprimir o núcleo central e a proposta de vida dos textos bíblicos, sem perder de vista o querigma. Para que possa cumprir com tal tarefa, se faz necessário uma hermenêutica bíblica que contribua com a homilia, ajudando-a a encontrar a mensagem proposta pelas Escrituras. Nesse trabalho, espera-se encontrar na hermenêutica de Paul Ricoeur tal contribuição. Por isso questiona-se: quais características e qual linguagem deve ter a homilia para que possa contribuir para a transmissão da fé na atualidade, segundo a Exortação Evangelii Gaudium? Como a hermenêutica bíblica em Paul Ricoeur pode contribuir para que a homilia cumpra seu papel segundo as orientações da Evangelii Gaudium?

Procurando responder, em primeiro lugar irá apresentar-se as características da homilia na Exortação Evangelii Gaudium, tentando compreender o que pede o Papa Francisco sobre o conteúdo e linguagem da homilia. Em segundo lugar, procura-se trazer elementos da hermenêutica bíblica de Paul Ricoeur e como eles contribuem para a finalidade da homilia. Por fim, volta-se a Evangelii Gaudium para apontar como deve ser a linguagem usada pelo pregador segundo a Exortação. Espera-se que o diálogo entre hermenêutica filosófica e hermenêutica bíblica possa contribuir para o anúncio do Evangelho hoje, e principalmente, auxiliar os pregadores em sua árdua tarefa.

\section{Características da homilia na Exortação Evangelii Gaudium}

O capítulo III da Exortação Evangelii Gaudium trata do anúncio do Evangelho. Dentro desse capítulo está o ensinamento do Papa Francisco sobre a homilia. Ela exprime a própria natureza da Igreja, que existe para evangelizar, para comunicar a Palavra de Deus, levar os homens ao conhecimento de Jesus Cristo por meio de seu anúncio explícito. 


\begin{abstract}
A Igreja é como que um sacramento de Cristo, a Palavra de Deus. Ela deve comunicativa, eloquente, no "anúncio do Evangelho". Ali se considera a necessidade da primazia do anúncio explícito de Jesus como Senhor. A Igreja escuta a Palavra de Deus e a transmite como discípula missionária. A "prioridade absoluta" (cf. EG 110) consiste no anúncio explícito de Jesus Cristo (BIANCHINI, 2015, p. 64).
\end{abstract}

Francisco endossa a importância da homilia como momento privilegiado de anúncio do Evangelho e de transmissão da fé. Certeza que a Igreja já apresentou em outros documentos. O Papa Bento XVI na Exortação Verbum Domini, que aborda a Palavra de Deus na vida e missão da Igreja, disse:

\begin{abstract}
A homilia constitui uma atualização da mensagem da Sagrada Escritura, de tal modo que os fiéis sejam levados a descobrir a presença e a eficácia da Palavra de Deus no momento atual da sua vida. Aquela deve levar à compreensão do mistério que se celebra; convidar para a missão, preparando a assembleia para a profissão de fé, a oração universal e a liturgia eucarística (Verbum Domini, 2010, n. 59).
\end{abstract}

Assim, Francisco dos números 135 a 159 da Evangelii Gaudium reafirma a importância da homilia no âmbito do anúncio da Palavra de Deus no contexto atual. O Papa se debruça sobre o tema da homilia e sua preparação, "porque muitas são as reclamações relacionadas a esse ministério importante, e não podemos fechar os olhos" (Evangelii Gaudium, 2013, n. 135). Para ele a pregação litúrgica faz a mediação entre o pastor e seu povo, ela é "um encontro consolador com a Palavra, uma fonte constante de renovação e crescimento" (Evangelii Gaudium, 2013, n. 135). O documento apresenta algumas características fundamentais que devem marcar a homilia no contexto hodierno.

Francisco caracteriza a homilia como uma conversa da mãe com seus filhos. "Lembra-nos que a Igreja é mãe e prega ao povo como uma mãe fala ao seu filho" (Evangelii Gaudium, 2013, n. 139). Já aqui se percebe a linguagem não rude que o Papa deseja que tenha a homilia, "esta linguagem é uma tonalidade que transmite coragem, inspiração, força, impulso" (Evangelii Gaudium, 2013, n. 139). Esta visão da Igreja materna que prega a seus filhos deve ser cultivada pelos próprios pregadores, estes precisam ser próximos dos ouvintes, utilizando uma linguagem que manifeste essa proximidade. Afirma Francisco: "deve ser encarecido e cultivado por meio da proximidade cordial do pregador, do tom caloroso da sua voz, da mansidão do estilo das suas frases, da alegria dos seus gestos" (Evangelii Gaudium, 2013, n. 139). Ele parte da certeza de que os conselhos de uma mãe, com o passar 
do tempo, dão fruto no coração dos filhos. A paciência da mãe deve acompanhar o pregador em seu ofício. E além da paciência materna, também a capacidade de dialogar com seu povo, como o próprio Deus se revelou a seu povo em um caminho de diálogo, entre revelação e resposta, assim sua Palavra deve continuar sendo anunciada num caminho dialógico. "O Senhor compraz-se verdadeiramente em dialogar com o seu povo, e compete ao pregador fazer sentir este gosto do Senhor ao seu povo" (Evangelii Gaudium, 2013, n. 141). Assim, deve a Igreja ao pregar, trazer a seus filhos uma proposta de vida plena, a novidade da Boa-Notícia, não se perdendo somente em apresentar obrigações morais.

Outra característica da homilia que Francisco chama a atenção na Evangelii Gaudium é a necessidade, de no contexto atual, todo o anúncio da Palavra de Deus, e também a homilia, partir do "coração do Evangelho". Essa expressão é usada pelo Papa nos números 34 a 39 da Exortação. Sobre a homilia, Francisco orienta:

\footnotetext{
Por exemplo, se um pároco durante um ano litúrgico, fala dez vezes sobre a temperança e apenas suas ou três vezes sobre a caridade ou sobre a justiça, gera-se uma desproporção, acabando obscurecidas precisamente aquelas virtudes que deveriam estar mais presentes na pregação e na catequese. E o mesmo acontece quando se fala da lei que da graça, mais da Igreja que de Jesus Cristo, mais do Papa que da Palavra de Deus (Evangelii Gaudium, n. 38).
}

Papa Francisco diz ser necessário que a pregação fique concentrada mais tempo e mais vezes no coração do Evangelho, para exprimi-lo. Outras verdades de fé são sempre importantes, porém, o conteúdo central da Boa-Nova deve estar presente no coração e na boca do pregador. Caso contrário, corre-se o risco de o Evangelho não ser apresentado aos fiéis como aquilo que é: Boa-Notícia da salvação em Cristo, proposta de uma vida plena em Cristo. Sobre isso, argumenta o Papa: "Neste núcleo fundamental, o que sobressai é a beleza do amor salvífico de Deus manifestado em Jesus Cristo morto e ressuscitado". Assim Francisco retoma o papel do querigma, primeiro anúncio de Jesus Cristo, na evangelização. A isto ele chama de coração do Evangelho. Este deve estar presente na homilia, e nela deve haver adequada proporção na frequência dos temas e nos acentos postos aos mesmos. Pois, "o Evangelho convida, antes de tudo, a responder a Deus que nos ama e salva, reconhecendo-o nos outros e saindo de nós mesmos para procurar o bem de todos" (Evangelii Gaudium, 2013, n. 39). 
Nesse sentido, deve o pregador cuidar para não falar excessivamente da moral cristã, não acentuar somente questões doutrinais e morais, pois assim não estará a anunciar o coração do Evangelho. Tal orientação do Papa implica em um estilo de linguagem, que além de materna, deve ser sóbria, isto é, centrada no núcleo fundamental do anúncio cristão. A Pontifícia Comissão Bíblica já orientou aos pregadores que sejam sóbrios nas palavras:

\begin{abstract}
A explicação que se dá dos textos bíblicos no decorrer da homilia não pode entrar em muitos detalhes. Convém então, colocar em evidência as contribuições principais desses textos, aqueles que são os mais esclarecedores para a fé e os mais estimulantes para o progresso da vida cristã, comunitária ou pessoal (PONTIFÍCIA COMISSÃO BIBBLICA, 2004, p. 270).
\end{abstract}

Assim, tal pregação da Palavra de Deus, que coloque no centro o coração do Evangelho, vai exigir do pregador uma séria hermenêutica bíblica. Uma interpretação que não se perca no moralismo, mas que apresente a novidade de vida que o texto bíblico revela para o homem hodierno. Por isso, "São necessários princípios hermenêuticos válidos. A falta de preparação neste domínio provoca uma tentativa de renúncia a um aprofundamento das leituras bíblicas contentando-se em moralizar ou em falar de questões atuais sem iluminá-las pela Palavra de Deus” (PONTIFÍCIA COMISSÃO BÍBLICA, 2004, p. 271). É da interpretação feita das Sagradas Escrituras que irá também depender a fidelidade do pregador ao próprio Evangelho que ele anuncia, que é Boa-Notícia e dom de Deus, e não um código de condutas morais. "Uma insistência unilateral sobre as obrigações que se impõem aos fiéis deve seguramente ser evitada. A mensagem bíblica deve conservar seu caráter principal de boa nova da salvação oferecida por Deus" (PONTIFÍCIA COMISSÃO BIBLICA, 2004, p. 271).

A Evangelii Gaudium afirma que o pregador deve estar seguro de compreender adequadamente o significado das palavras que lê. O texto bíblico, escrito em outro contexto histórico, em cultura e linguagem desconhecida, precisa ser entendido em sua mensagem central. "Mas o objetivo não é o de compreender todos os pequenos detalhes de um texto; o mais importante é descobrir qual é a sua mensagem principal” (Evangelii Gaudium, 2013, n. 147). Encontrar tal mensagem garantirá uma pregação bem ordenada. Francisco aconselha: "Um dos defeitos de pregação enfadonha e ineficaz é precisamente não poder transmitir a força própria do texto que foi proclamado" (Evangelii Gaudium, 2013, n. 158). 
Assim, é necessária uma hermenêutica bíblica que contribua com essa missão do pregador na homilia. Por isso, volta-se agora ao pensamento hermenêutico de Paul Ricoeur, esperando-se encontrar em sua reflexão uma interpretação bíblica que possa contribuir com a missão atual da homilia de encontrar no texto bíblico a Boa-Nova, para então anunciá-la.

\section{Contribuição da hermenêutica bíblica de Paul Ricoeur}

A Pontifícia Comissão Bíblica, no documento A interpretação da Bíblia na Igreja, cita Paul Ricoeur como um dos representantes da hermenêutica filosófica moderna que pode contribuir para a hermenêutica bíblica. "[...] diversos autores aprofundaram a teoria hermenêutica contemporânea e suas aplicações à Escritura. Entre eles mencionaremos Rudolf Bultmann, Hans Georg Gadamer e Paul Ricoeur" (PONTIFÍCIA COMISSÃO BÍBLICA, 2004, p. 223). Assim, percebe-se uma contribuição de sua filosofia, que tem incidência sobre a interpretação dos textos bíblicos.

Pretende-se trazer elementos da hermenêutica bíblica ricoeuriana que podem contribuir para que a pregação, segundo Francisco, atinja sua finalidade. Aqui, se limita a abordar resumidamente aspectos de sua hermenêutica bíblica, sem explicar aspectos da hermenêutica filosófica. No entanto, se faz necessário dizer que Ricoeur reconhece uma inclusão mútua entre as duas hermenêuticas, aplicando a contribuição da hermenêutica filosófica ao fazer hermenêutica bíblica, e ao mesmo tempo, reconhecendo o que a hermenêutica bíblica possui de próprio.

Das narrativas bíblicas o Reino de Deus é para ele o elemento comum, ou o símbolo que pode ser sempre ressignificado. Em termos filosóficos, é a "coisa do texto", o objeto da hermenêutica.

Ao dizer que o Reino de Deus é o elemento comum a vários modos de discurso, de modo algum pretendo subentender que seja o referente último das palavras, provérbios ou ditos proclamatórios, que falam dessa noção de uma forma ou de outra. Chamando-o "qualificador" de cada um desses modos de discurso, trata-o como um símbolo que requer uma interpretação capaz de fazer dele uma parte do sentido da parábola, do provérbio ou do dito proclamatório (RICOEUR, 2006, p. 136-137, apud PAULA, 2012, p. 246). 
A linguagem teológica e bíblica fornece palavras e símbolos que precisam ser significados e ressignificados. Precisam então, de um sistema interpretativo que respeite sua natureza. Ricoeur reconhece a confissão de fé como ponto fundamental e próprio do texto bíblico. "A confissão de fé que se exprime nos documentos bíblicos é inseparável das formas de discurso, quero dizer, a estrutura narrativa, por exemplo, do Pentateuco e dos Evangelhos, a estrutura oracular das profecias, a parábola, o hino, etc" (RICOEUR, 2006, p. 126). Assim, há entre a confissão de fé e as narrativas bíblicas uma solidariedade. Do que se diz sobre Deus nas lendas e sagas isoladas, são no fundo organizadas para construir uma única narrativa, "centrada num acontecimento-núcleo que tem, ao mesmo tempo, um alcance histórico e uma dimensão kerigmática" (RICOEUR, 1989, p. 127). Liga-se dessa forma a dimensão narrativa com a dimensão querigmática. Como que um núcleo que dê sentido e significado a todas as narrativas.

Da hermenêutica bíblica em Paul Ricoeur irá se destacar quatro elementos que se consideram importantes ao objetivo desse trabalho, sobretudo de seu texto Hermenêutica filosófica e hermenêutica bíblica.

Primeiramente, o reconhecimento de Ricoeur de que a teologia cristã primitiva, que elaborou os textos bíblicos, diverge-se da filosofia grega. A teologia primitiva não reconhece nada ainda "dos conceitos de causa, fundamento, de essência; ela fala de Deus de acordo com o drama histórico instaurado pelos actos de libertação que a narrativa refere" (RICOEUR, 1989, p. 128). O modo de falar de Deus na Bíblia não é inferior ao dos gregos, mas é uma forma própria. Sabe-se que ao longo da história, o Deus da Bíblia foi recebendo roupagem filosófica e dogmática. Contudo, para Ricoeur, a narrativa da Bíblia fala de Deus a partir de uma experiência histórica. A forma do discurso é narrativa, mas o conteúdo do discurso é a confissão de fé da comunidade, perante um acontecimento, como o Êxodo por exemplo. Então, daí resulta também um estilo de pregação histórico e existencial, para que o texto bíblico fale ao hoje dos ouvintes. A pregação é anúncio a partir de uma narrativa de salvação operada por Deus e testemunhada pela comunidade de fé. Discernir o acontecimento salvífico na narrativa bíblica é desafio do exegeta e do pregador.

Em segundo, Ricoeur aplica a hermenêutica filosófica à Bíblia no que diz respeito à "fala-escrita". A hermenêutica filosófica orienta a hermenêutica bíblica que não faça um discurso teológico que não leve em conta a passagem ocorrida da 


\section{8 | Opinião Filosófica, V. 11, 2020 - Dossiê Teologia \& Linguagem}

fala à escrita. Ricoeur reconhece aqui, que para a teologia a Palavra é anterior a Escritura. Afinal de contas, a escrita é precedida por uma fala. Jesus foi um pregador e não escritor, e os cristãos viram nele a Palavra feito carne. "É assim que a teologia cristã se chama, voluntariamente, 'teologia da palavra', unindo sob este vocábulo a origem da sua fé, o objeto da sua fé, a expressão da sua fé, tornando-se todos estes aspectos da fala um único 'acontecimento de fala”" (RICOEUR, 1989, p. 129). Assim, ele evidencia em sua exegese algo fundamental para a pregação cristã: a Palavra de Deus é viva, é um acontecimento, um fato, em Cristo é uma pessoa, para depois, ser escrito o testemunho daqueles que a viram.

Deste aspecto, ressalta-se ainda que a pregação cristã sempre repousou sobre os testemunhos interpretados pela comunidade primitiva. O texto bíblico traz consigo testemunho e também já interpretação do testemunho pela comunidade. Essa relação fala-escrita é constitutiva da pregação e do querigma. Este começa como proclamação e fala, mas "graças à escrita, a fala estende-se até nós e atingenos pelo seu 'sentido' e pela ‘coisa' de que se trata nela e já não pela 'voz' do seu proclamador” (RICOEUR, 1989, p. 130). Graças a escrita do texto bíblico o querigma chega até incontáveis gerações. Ele é a "coisa do texto", na linguagem ricoeuriana, que precisa ser sempre encontrado. Essa é a categoria central de sua hermenêutica, tanto filosófica quanto bíblica: a "coisa do texto" ou o "mundo do texto".

A partir disso, há o terceiro elemento que precisa ser destacado da hermenêutica de Ricoeur. "A primeira tarefa da hermenêutica não é suscitar uma decisão do leitor, mas, em princípio, deixar explanar-se o mundo de ser que é a 'coisa' do texto bíblico” (RICOEUR, 1989, p. 132). O leitor, diante do texto, é colocado perante um mundo novo, o "mundo do texto”. Na linguagem bíblica esse mundo novo é chamado de nova Aliança, ou Reino de Deus, ou novo nascimento. É a proposta de vida nova que Deus oferece ao homem. "Está aí aquilo que podemos chamar a 'objectividade', do ser novo projectado pelo texto" (RICOEUR, 1989, p. 132).

Deriva-se dessa visão, que a exegese ajuda a pregação a encontrar na Bíblia o que ela traz de novo ao homem, isto é, o Reino de Deus, a oferta de salvação por Deus ao homem, a Boa-Nova da salvação. O intérprete das Escrituras tem diante de si uma proposta de mundo novo proposto pelo texto. Um mundo novo que permite um ser novo. 
Da mesma forma que o mundo do texto literário é um mundo projetado, que se distancia poeticamente da realidade cotidiana, em linguagem teológica, quando se afirma que o Reino de Deus vem, este também é um mundo possível, projetado, que se distancia da realidade cotidiana (PAULA, 2012, p. 247).

Perante essa proposta de mundo novo feita pelo texto bíblico, só então o ouvinte tomará uma decisão. Compreendendo-se diante do texto, o sujeito poderá dar uma resposta. Assim, as implicações éticas vêm por consequência da pregação, mas não são o primeiro objetivo da hermenêutica. Ela deve em primeiro lugar, ajudar a encontrar o sempre novo da mensagem bíblica, a que o leitor ou o ouvinte poderá acolher ou não.

E como quarta e última implicação da hermenêutica bíblica de Ricoeur está a globalidade do horizonte bíblico. A revelação bíblica traz consigo contrastes. Por exemplo, o mesmo Deus faz promessas de destruição e de vida plena ao homem. Essa variedade de significações mostra que o mundo do texto bíblico é um mundo de horizonte global.

O mundo bíblico tem aspectos cósmicos - é uma criação - comunitários trata-se de um povo - histórico-culturais - trata-se de Israel, do Reino de Deus - e pessoais. O homem é atingido nas suas múltiplas dimensões que são cosmológicas, histórico-mundiais, tanto como antropológicas, éticas e personalistas (RICOEUR, 1989, p. 133).

Para Ricoeur, a Bíblia fala ao homem integral. O discurso bíblico, e por consequência a pregação bíblica, não traz implicações somente sociais, ou somente comunitárias, ou somente pessoais e psicológicas. Assim, o mundo do texto bíblico não pode ser reduzido a uma dessas interpretações, não pode ser sequestrado pela intenção do leitor e do pregador. Mas a mensagem bíblica traz consigo todos esses aspectos. Tal característica precisa ser também levada em conta pelo pregador, para que não use do texto bíblico somente para legitimar suas ideias ou opiniões pessoais, e para que a pregação não se deixe levar por tendências somente psicológica e personalística, ou somente política e social. O mundo bíblico abarca diversas dimensões e propõe essa riqueza ao leitor, que pode aplicá-la em diversas situações.

Outras implicações da hermenêutica bíblica de Paul Ricoeur poderiam ser trazidas aqui, contudo, entende-se serem essas suficientes para perceber como sua interpretação bíblica vai ao encontro da função da homilia conforme pede o Papa Francisco em sua primeira Exortação. A pregação cristã deve ajudar o ouvinte a 
"compreender-se diante do texto", numa linguagem ricoeuriana, ter sua subjetividade mudada pela proposta de mundo do texto bíblico.

Aquilo que eu, finalmente me aproprio, é uma proposta do mundo; não está atrás do texto, como estaria uma intenção encoberta, mas diante dele como aquilo que a obra desenvolve, descobre, revela. A partir daí, compreender é compreender-se diante do texto. [...] A compreensão é, então, exatamente o contrário de uma constituição de que o sujeito teria a chave. Seria, nesta perspectiva, mais justo dizer que o si é constituído pela "coisa" do texto (RICOEUR, 1989, p. 124).

Agora, amparados pela hermenêutica de Ricoeur, faz-se necessário, retornar a Evangelii Gaudium, para encontrar implicações práticas para a linguagem que deve usar o pregador na homilia, afim de fazer ressoar o coração da mensagem bíblica.

\section{A linguagem da homilia}

Voltando-se agora para a questão da homilia na Evangelii Gaudium, ressalta-se que a Exortação, ao tratar do anúncio do Evangelho no mundo atual, não trouxe soluções acabadas para os desafios atuais da evangelização. Antes, ela oferece pistas e aponta horizontes. Ao falar da homilia, Francisco reafirma sua importância no contexto atual, e se faz a necessária uma hermenêutica bíblica capaz de encontrar o coração do Evangelho, e assim ajudar os pregadores no anúncio da Boa-Nova. Quanto a linguagem da homilia para o anúncio do Evangelho hoje, o Papa indica algumas características, que serão agora resumidamente abordadas. São elas: linguagem simples e dialogal, linguagem querigmática, linguagem sóbria e linguagem positiva.

\section{Simples e dialogal}

A Evangelii Gaudium trata da linguagem dialogal da homilia, no sentido de que não somente o pregador fala ao povo, mas ele próprio deve primeiro, ouvir o povo. Escutar deve ser a primeira atitude do pregador. "O pregador deve também pôr-se à escuta do povo, para descobrir aquilo que os fiéis precisam ouvir. Um pregador é um contemplativo da Palavra e também um contemplativo do povo" (Evangelii Gaudium, 2013, n. 154). O esforço da homilia é de relacionar a 
mensagem do texto bíblico com a situação humana, relacionar o Evangelho com a vida concreta das pessoas. Isso exige interpretação bíblica e também conhecer a comunidade a quem está pregando. A mensagem bíblica, conforme também a hermenêutica de Ricoeur, é sempre atual, traz uma proposta nova a quem está perante o mundo do texto bíblico, e que precisa da luz da Palavra.

A atitude de ouvir o povo está fundamentada na teologia do sensus fidei. Nela, sabe-se que todo fiel é disposto a uma atitude de discípulo da Palavra, desde o batizado mais analfabeto até o maior doutor, o Espírito Santo dotou a todos de uma sensibilidade para escutar e discernir a Palavra de Deus. Deus dota a totalidade dos fiéis com um instinto da fé, que ajuda a discernir o que realmente vem de Deus. Assim, "o pregador deve pôr-se à escuta do povo, para descobrir aquilo que os fiéis precisam ouvir" (Evangelii Gaudium, 2013, n. 154), e também descobrir o que os fiéis sabem pelo instinto da fé, mesmo que seja algo simplesmente vivido no seu cotidiano. Para Francisco quando o pregador dialoga com a comunidade, ele não somente conhece o terreno onde irá lançar a semente da Palavra, mas Deus fala ao pregador por meio do povo.

Para que a homilia seja compreendida pela comunidade ouvinte ela deve ser simples. Papa Francisco pede que a pregação tenha simplicidade na linguagem. "Deve ser simples para que os destinatários compreendam, para não correr o risco de falar ao vento" (Evangelii Gaudium, 2013, n. 158). O pregador deve ter atenção de não usar palavras comuns nos seus estudos teológicos, mas que a maioria da assembleia não compreende. "O maior risco de um pregador é habituar-se à sua própria linguagem e pensar que todos os outros a usam e compreendem espontaneamente" (Evangelii Gaudium, 2013, n. 158). É ouvindo o povo que o pregador irá desenvolver linguagem que seja compreensível.

\section{Querigmática}

Deriva da simplicidade da pregação a linguagem querigmática. A Evangelii Gaudium retoma a centralidade do querigma na ação evangelizadora, e com isso a missão dos pregadores de anunciarem o coração do Evangelho, como já foi abordado nesse trabalho. Não deve a homilia perder-se em temas que não exprimam o centro das Sagradas Escrituras: o amor salvífico de Deus em Cristo, as consequências morais são posteriores. 
No que diz respeito à maneira de comunicar o Evangelho aos outros, o texto não deixa dúvida alguma sobre dois pontos essenciais: "enfrentando o risco de seleção interessada", inerente aos meios contemporâneos de comunicação, ele convida os pregadores a relacionarem todos os "aspectos secundários" com o "coração do Evangelho" (n. 34-39) - a célebre "hierarquia das verdades" (UR, n. 11) apoiada em Santo Tomás (n. 37) (THEOBALD, 2015, p. 16).

Para Francisco existem aspectos secundários, na doutrina e moral cristãs, que por si mesmos não expressam o coração da mensagem de Jesus Cristo. Precisam ser ligados a esta mensagem para fazerem sentido e tornarem-se salvíficos na vida que as ouve. "Convém, portanto, ser realistas e não dar por suposto que os nossos interlocutores conhecem o horizonte completo daquilo que dizemos ou que eles podem relacionar o nosso discurso com o núcleo essencial do Evangelho que lhe confere sentido, beleza e fascínio" (Evangelii Gaudium, 2013, n. 34). Assim, é preciso uma linguagem na homilia que se concentre no essencial, no que é belo e mais importante. "A proposta acaba simplificada, sem com isso perder profundidade e verdade, e assim se torna convincente e radiosa" (Evangelii Gaudium, 2013, n. 35).

\section{Unidade temática}

Outra característica da linguagem da homilia conforme a Evangelii Gaudium é a unidade temática. Ela deriva da hermenêutica bíblica que chega ao núcleo da mensagem, e por isso não se perde em muitos e variados temas. Com auxílio da interpretação o pregador consegue encontrar o tema central dos textos. Ter um único tema confere a homilia a clareza. Conforme Francisco, além de simples, ela deve ser clara em sua linguagem. Nem sempre o que é simples é claro. As duas características precisam andar juntas. O Papa alerta: "Pode-se tornar incompreensível pela desordem, pela sua falta de lógica, ou porque trata de vários temas ao mesmo tempo" (Evangelii Gaudium, 2013, n. 158). Por isso, é preciso que a pregação tenha unidade temática, uma ordem clara e ligação entre as frases, de modo que os ouvintes possam acompanhar a lógica do raciocínio do pregador.

\section{Linguagem positiva}

Outra característica que Francisco propõe para a homilia no contexto atual é 
que tenha linguagem positiva. Ela é consequência também da hermenêutica bíblica que chega ao mundo proposto pela mensagem das Escrituras, pois a Bíblia comunica a mensagem da salvação, portanto, uma Boa-Nova. Seria contraditório anunciar uma boa-notícia com uma linguagem pessimista e negativa.

A linguagem positiva da homilia diz respeito ao aspecto moral da pregação. "Não diz tanto o que não se deve fazer, mas sobretudo propõe o que podemos fazer melhor. E, se aponta algo negativo, sempre procura mostrar também um valor positivo que atraia, para não se ficar em queixa, lamento, crítica ou remorso" (Evangelii Gaudium, 2013, n. 139). Uma linguagem positiva na homilia exprime o coração do Evangelho, traz esperança, ilumina as situações difíceis dos ouvintes com um mundo novo diante dele. Sobre uma linguagem positiva na pregação, a Pontifícia Comissão Bíblica diz: “A pregação fará trabalho mais útil e mais conforme a Bíblia se ele ajudar primeiramente os fiéis a 'conhecer o dom de Deus' (Jo 4, 10), tal como ele é revelado na Escritura, e a compreender de maneira positiva a exigências que decorrem disso" (PONTIFÍCIA COMISSÃO BÍBLICA, 2004, p. 271).

\section{Conclusão}

A Exortação papal Evangelii Gaudium, ao tratar da evangelização no mundo atual, dá ênfase a homilia como momento privilegiado de anúncio da Palavra de Deus. A Exortação convida a Igreja a voltar ao querigma, ao coração do Evangelho, para que a pregação da Palavra não seja discurso abstrato e distante, mas tenha implicações salvíficas para as pessoas, seja de fato apresentado como Boa-Nova.

Encontrar a mensagem central dos textos bíblicos de uma celebração litúrgica consiste em um desafio aos pregadores. Haveria tanto a falar, tanto a catequizar os ouvintes, tanto a exortar. Contudo, Papa Francisco convida a voltar ao essencial do anúncio cristão. Espera-se ter encontrado na hermenêutica de Paul Ricoeur o auxílio hermenêutico de que é possível encontrar o novo na mensagem bíblica. Procurar no texto a Palavra, e aproximar-se dele com abertura e humildade, para descobrir sua proposta de mundo, é um dos desdobramentos de sua teoria interpretativa.

Anunciar a Boa-Nova da salvação com linguagem sóbria e 13ncontra-la na Sagrada Escritura ajuda a fazer um elo de ligação entre a teologia e a filosofia hermenêutica. É a razão contribuindo com a fé. Lembrando, que pode-se também 
encontrar auxílio hermenêutico em outros filósofos da linguagem. Citou-se aqui Paul Ricoeur, mas existem outras filosofias que podem contribuir com a Igreja em sua exegese, como Gadamer. Indica-se pesquisas também sobre o seu contributo para a pregação cristã.

\section{Referências}

BENTO XVI. Exortação Apostólica Pós-Sinodal Verbum Domini: sobre a Palavra de Deus na vida e na missão da Igreja. Brasília: CNBB, 2010.

BIANCHINI, Wagner Cardoso. A Alegria do Evangelho e a eclesiologia do Povo de Deus. 2015. 114 f. Dissertação (Mestrado em Teologia) - Faculdade de Teologia, Pontifícia Universidade Católica do Rio Grande do Sul, Porto Alegre, 2015.

FRANCISCO. Exortação Apostólica Evangelii Gaudium: sobre o anúncio do Evangelho no mundo atual. São Paulo: Loyola, 2013.

PAULA, Adna Cândido. A teoria da interpretação e a hermenêutica bíblica de Paul Ricoeur. 2012. Teoliterária. Revista da Pontifícia Universidade Católica de São Paulo. São Paulo, n. 4, v. 2., p. 240-252, nov. de 2012.

PONTIFÍCIA COMISSÃO BÍBLICA. A interpretação da Bíblia na Igreja. Documentos sobre a Bíblia e sua interpretação (1893-1993). São Paulo: Paulus, 2004.

RICOEUR, Paul. A função hermenêutica da distanciação. Do texto a acção: ensaios de hermenêutica II. Porto (Portugal): RÉS [1989]. p. 109-124.

RICOEUR, Paul. A hermenêutica bíblica. Trad. Paulo Meneses. São Paulo: Edições Loyola, 2006.

THEOBALD, Christoph. A exortação apostólica Evangelii Gaudium: Esboço de uma interpretação original do Concílio Vaticano II. Cadernos Teologia Pública. Revista do Instituto Humanitas Unisinos. São Leopoldo, v. 12., n. 104, p. 3-21, 2015.

Recebido em: 23/07/2020. Aprovado em: 27/07/2020. Publicado em: 28/07/2020. 